\title{
Reply-Acknowledging Intersectionality and Historical Context in Medical Education Research
}

J Gen Intern Med 35(10):3096

DOI: $10.1007 / \mathrm{s} 11606-020-06072-\mathrm{x}$

(C) Society of General Internal Medicine 2020

\section{To}

O THE EDITORS:

We appreciated the response to our piece by Tiako et al. We have no major disagreement with anything they have written. There is much to be gained by approaching questions through an intersectional lens and by putting findings into social and historical context.

For the purposes of furthering improvements in research, we do believe the difficulty of operationalizing their ideas bears mentioning. In our case, one of the largest challenges came in recruiting non-White participants, which, despite our intentions, precluded us from meaningfully analyzing the simultaneous effects of medical student race and gender on participants' responses. There are likely several explanations for this barrier. White individuals (especially males) have long been overrepresented in internet samples, ${ }^{1,2}$ and historical injustices may have made Black participants wary of partaking in a survey sponsored by a hospital. ${ }^{3}$ We provide this example to highlight how generating research that is generalizable and concurrently able to address social complexities via the internet will require more than the intentions of individual researchers. Among other action items, it will require having groups that the scientific community has historically wronged in leadership positions to guide improvement efforts in addition to resources dedicated to recruiting underrepresented research participants.

Additionally, we also agree a robust discussion section can help inform hypothetical explanations for a study's results, but feel the lack of an extensive exploration of context should not overshadow the results themselves. Entire books are written on the intersection of society and medicine. E.O. Wilson puts it concisely in Consilience: The Unity of Knowledge when he states "[The] social sciences are hypercomplex. They are inherently far more difficult than physics and chemistry, and as a result they, not physics and chemistry, should be called the hard sciences." No discussion section in an original article, let alone one in a research letter, can ever be incontrovertibly complete, but that should not diminish what can be learned

Published online August 4, 2020 from a study's results. We feel this is especially true of studies exploring the intersection of medical education and society, which are published in limited numbers, and of our study specifically, which differs from the usual small, single-center studies that characterize much of the literature on this topic. In our case, even a subtle experiment elicited demographic preferences from respondents. Medical schools should dedicate resources to assessing how these preferences may affect their own students, and we hope future work uses an intersectional lens to build upon this research.

Alexander Chaitoff, $M D, M P H^{1}$

Josephine Volovetz, MD, $\mathrm{MS}^{2}$

Blair Mitchell-Handley, $\mathrm{MD}^{3}$

${ }^{1}$ Department of Medicine, Brigham and Women's Hospital/Harvard Medical School,

Boston, MA, USA

${ }^{2}$ Department of Neurosurgery, Cleveland Clinic, Cleveland, $\mathrm{OH}$, USA

${ }^{3}$ Department of Obstetrics and Gynecology, Mercy Hospital and Medical Center,

Chicago, IL 60616, USA

Corresponding Author: Alexander Chaitoff, MD, MPH; Department of Medicine, Brigham and Women's Hospital/Harvard Medical School, Boston, MA, USA (e-mail: achaitoff@bwh.harvard.edu).

Funding Information This study is supported by the AAMC Central Group on Educational Affairs Mini-Grant.

Compliance with Ethical Standards:

Conflict of Interest: The authors declare that they do not have a conflict of interest.

\section{REFERENCES}

1. Kaye BK, Johnson TJ. Research methodology: taming the cyber frontier: techniques for improving online surveys. Soc Sci Comput Rev 1999; 17(3):323-337.

2. Levay KE, Freese J, Druckman JN. The demographic and political composition of Mechanical Turk samples. Sage Open 2016;6(1):2158244016636433.

3. Corbie-Smith G, Thomas SB, Williams M V, Moody-Ayers S. Attitudes and beliefs of African Americans toward participation in medical research. J Gen Intern Med 1999;14(9):537-546.

4. Wilson EO. Consilience: The Unity of Knowledge. Vol 31. Vintage; 1999.

Publisher's Note Springer Nature remains neutral with regard to jurisdictional claims in published maps and institutional affiliations. 